\title{
Integrating Early Neutral Evaluation into Mediation of Complex Civil Cases in Malaysia
}

\author{
Norman Zakiyy J. T. Chow ${ }^{1} \&$ Kamal Halili Hassan ${ }^{1}$ \\ ${ }^{1}$ Faculty of Law, National University of Malaysia, Bangi, Malaysia \\ Correspondence: Norman Zakiyy J. T. Chow, Faculty of Law, National University of Malaysia, 43600 UKM \\ Bangi, Selangor, Malaysia. Tel: 60-12-687-3368. E-mail: zakiyy@usim.edu.my
}

Received: July 15, 2014 Accepted: September 2, 2014 Online Published: November 19, 2014

doi:10.5539/jpl.v7n4p138 URL: http://dx.doi.org/10.5539/jpl.v7n4p138

\begin{abstract}
Early Neutral Evaluation and mediation are claimed to be suitable alternative dispute resolution mechanisms for resolving a myriad of civil cases. Regrettably, very little information is known as to how viable is the combining of these two mechanisms in resolving complex civil cases in Malaysia. The purpose of this study was to explore the viability of Early Neutral Evaluation and mediation in resolving complex civil cases. This study investigated the distinctive features and goals of Early Neutral Evaluation; and circumstances which provide the possibility for the referral of Early Neutral Evaluation in supporting the process of mediating complex civil cases in the civil courts of Malaysia. This study found that, subject to certain modification of the Rules of Court 2012, Early Neutral Evaluation can be used as a viable mechanism to resolve complex civil cases. The referral to Early Neutral Evaluation also improves and supports the understanding of the disputants on the issues surrounding complex cases in a follow-up mediation session. It is expected that this study will contribute significantly to developing a model for resolving complex civil cases involving the referral of Early Neutral Evaluation and mediation in Malaysia.
\end{abstract}

Keywords: complex, civil cases, early neutral evaluation, mediation, Malaysia

\section{Introduction}

In the late 1980s, the Malaysian Judiciary faced deteriorating performance and delay in the disposal of cases (World Bank, 2011). In 2000, pre-trial case management was introduced to manage civil proceeding under the old dominions of the High Court 1980 ("RHC 1980"). Court procedures were then monitored under the watchful eyes of judges to avoid delay in case disposal. Unfortunately, the impact of such action was marginal. It was in October 2008 that Tun Zaki Tun Azmi, the former Chief Justice of Malaysia introduced e-court and the "Court Backlog and Delay Reduction Programme" (Court Reform Programme). The initial aim of the e-court and the Court Reform Programme were to reduce backlog and accelerate the process of disposal of new cases.

Case management system ("CMS") is one significant component of the e-court and was introduced to improve the handling of cases (Hassan, Yusoff, Mokhtar, \& Khalid, 2012). Practically, the CMS is widely applied in pre-trial case management and application for a full trial (Hassan et al., 2012). On August 1, 2012, the Rules of Court 2012 ("RC 2012") was introduced to replace the RHC 1980 and place a uniform procedural set of rules for the high courts and the subordinate courts (session courts and magistrates' courts). It is interesting to note that during the pre-trial case management stage, the Court may consider any matter such as from admitting the possibility of settlement of all or any of the issues in the action or proceedings to the utilization of mediation (Order 34, rule 2 (a) of the RC 2012). In Malaysia, mediation is an integral part of the pre-trial procedure in civil litigation under the RC 2012 (Hamid, 2012). Apparently, in Malaysia, mediation is also used to clear backlog of cases pursuant to the Federal Court's Practice No.5 of 2010. In line with the exertion of the court to encourage the utilization of mediation, Court Connected-Mediation was introduced in 2010.

The promises of mediation have mesmerised many. Several Malaysian authors have advanced the idea of introducing mediation on a mandatory basis (Examples: Wahab, 2013a; Nawi \& Abdul Hak, 2013). In the west, however, there are mixed reactions as to the effectiveness of mandatory mediation. Jacobs (2005) and Kelly (1994) endorse the idea of making mediation a mandatory court-connected programme. Wissler (2002) opines that mediation has been procedurally just, involved party participation, not coercive; and resolves cases. Several legal commentators, however, put forward legitimate concerns about mandatory mediation. Alexander (1999) 
emphasises that "any meaningful evaluation of mediation compared to litigation is hindered by theoretical and practical problems." A smattering of other commentators such as Bryan (1992) and Fiss (1984) hold strongly to the belief that mediation is less legalistic and thus tend to unjustifiably influence disputants into accepting an unfair arrangement. Correspondingly, the concerns about the practice of mediation in Malaysia are also aplenty. For example, the World Bank reported that mediated cases appeared to be low (World Bank, 2011). Wahab (2013b) in his thesis on court-annexed mediation and judge-led mediation in Malaysia found that judges, lawyers and the public resisted mediation; and that the public lack knowledge of mediation apart from believing that the judge is the ultimate decision maker to their dispute.

In general, non-complex cases (or simply known as pure and simple cases) are geared towards early resolution under the Malaysian e-courts. This category of cases would normally be thrown out inside the required timeline of between nine (9) months to twelve (12) months, especially with the support of CMS. For instance, in Petroliam Nasional Bhd v. Perwaja Steel Sdn. Bhd. [2013] 8 CLJ 391, Nallini Pathmanathan, J., in delivering the judgment of the High Court of Kuala Lumpur observed at p. 416 that the case involved a question of law and the facts are not triable and could be easily determined by a "consideration of the contract, the factual background and an application of the correct principles of law on the construction of a commercial contract." In a non-complex case, mediation can also be an alternative way of resolution.

Lately, however, complexity in civil proceedings has been a subject of serious consideration by the Malaysian courts as evidenced by a few recently decided cases. In Positive Well Marketing Sdn. Bhd. v. OKA Concrete Industries Sdn. Bhd. [2013] 8 CLJ 1083, Ummi Kalthum Abdul Majid, J. decided that the case argued before she was complex because it involved a difficult question of law and required substantial and specialised knowledge and responsibility to conduct the case). Similarly, in Khairy Jamaluddin v. Dato' Seri Anwar Ibrahim [2013] 6CLJ 849, Anantham Kasinather, JCA, in delivering the judgment of the court (at p.850) held that "The issues of law stated here were not just issues which at the first blush appeared complex but were genuinely complex and required careful consideration by the High Court". These decisions tend to indicate that the courts recognise the need to give extra judicial attention to the administration of such category of cases. As previously mentioned, mediation has been used as the forefront by the judiciary. But nevertheless, the aforesaid "complex cases" were not referred to mediation.

In the light of the above situation, it can be concluded that complex cases are understood as part and parcel of civil litigation in Malaysia. Notably, the World Bank Report does not remark about any effort of the Court Reform Programme to manage problems associated with complex cases. Besides that, it is also unknown whether mediation is suitable to be cited in a diversity of complex cases in Malaysia. In contrast, Early Neutral Evaluation (ENE), is less known in Malaysia as well as in certain parts of the globe, especially in the Asian region. Nevertheless, ENE is currently practiced in many developed nations such as the United States, England, Australia and Singapore. Kornblum (2012) suggests the utilization of a combination of ADR mechanisms in the settlement of conflicts. Engro and Lenihan (2008a) suggest that ENE is fairly suitable in resolving "complicated and unusual cases" which involve "mixed issues of facts and law, unclear damage issues, challenging evidential issues or cases which require the expert's opinion." Alas, their shared opinion found little support from empirical surveys. It is likewise evidence that in the United States, many courts have used ENE along with other ADR mechanisms to solve complex cases. Therefore, the aim of this study was to research the viability of ENE as an efficient mechanism to support, mediation in settlement of complex civil cases in Malaysia's civil courts. This study was based on library research. Data was collected electronically (via the internet) as well as manually from various sources (mainly from journals, researches, books, court rules and articles). This study emphasizes on the practice of ENE in the United States, being its place of inception and partly due to its active referral in case planning and settlement.

\section{Early Neutral Evaluation}

\subsection{Description}

"Neutral evaluation" encompasses the terms consisting of Early Neutral Evaluation (ENE), neutral valuation, and non-judicial settlement conferences and is described as "[a] process in which an expert [n]eutral receives a presentation about the merits from each side and attempts to evaluate the presentations and predict how a court would decide the matter." (Tenille, Applebaum \& Nees, 2010). A significant number of legal commentators have also attempted to classify ENE as an ADR mechanism. Maycock (2011a) opines that ENE has grown in popularity and is at par with mediation and arbitration. Nor Fadzlina Nawi et al. (2013) cites earlier writings of Goldberg et al. (2007) that describes the term ADR to cover a wide variety dispute resolution mechanism "that 
are short of, or alternative to, full-scale court processes which consist of early neutral evaluation, arbitration, ombudsman and mediation".

\subsection{Development of Early Neutral Evaluation}

ENE has blossomed in the United States for the past decades. ENE started off as a court programme in the United States District Court for the Northern District of California (NDCA) in the 1980s (Brazil, 1990a). ENE has been in use since 1985 in the Northern District of California (Dayton, 1991). As of to-date, in the United States alone, ENE has been introduced as a court ADR programme in nearly 22 states. These include the states of California, Alaska, Connecticut, Delaware, Indiana, Kansas, Massachusetts, Montana, to mention a few. These states offer ENE in civil matters. Over the past years, ENE has gained considerable recognition. It has been replicated in several jurisdictions, such as in England, Australia and Singapore. In the United States, the Alternative Dispute Resolution Act of 1998 (ADR Act of 1998) authorizes each United States District Court to require litigants in all civil cases to consider the use of ADR procedure. It provides the framework by which each district court should promulgate procedures and rules regarding the ADR process within its jurisdiction. Although other forms of Alternative Dispute Resolution mechanisms such as arbitration, Early Neutral Evaluation (ENE), settlement conferences and summary jury trials are used in the United States, it is worth noting that mediation is the most favoured mechanism referred to in the settlement of disputes.

\subsection{Distinctive Features of Early Neutral Evaluation Compared to Mediation}

This section discusses about the theoretical aspect of ENE. In appropriate situations, a discussion on mediation (especially in conditions of compatibility) is likewise included in order to differentiate it from the former, apart from defining in what ways ENE can support the process of mediating complex cases.

Some of the distinctive features of an ENE conference are identified below:

\subsubsection{Confidential and Non-Binding}

Legal commentators are of the view that the neutral evaluator would provide a non-binding evaluation to disputants (Brazil, 1990b; Welsh, 2011). The confidential and non-binding outcome of the ENE Conference is to a certain extent similar to a mediation session. The confidential nature of the ENE Conference has received statutory recognition as stated under the United States District Court, Northern District of California under its ADR Rules, 5-12. It has also received judicial recognition as exemplified in the case decided in the United States District Court, Northern District of California, notably, In Re Prohibition Against Disclosing ENE Communications To Settlement Judges (494 F.Supp.2d 1097). In this case, Wayne Brazil, United States Magistrate Judge, held that: "in the absence of a stipulation of all parties and the evaluator, the ADR Local Rules prohibit a party from disclosing to a settlement judge any communication made in connection with an Early Neutral Evaluation (ENE) session and any view expressed by an evaluator."

\subsubsection{Settlement Discussions (Prior or After Evaluation Exercise, If Desired by Client)}

Settlement is an important aim of a mediation session and the mediator facilitates the disputants in reaching settlement. Pearson (2006a) refers ENE as a "confidential, settlement-oriented and accelerated alternative dispute resolution technique". Stradley, Ronan, Steven and Young, LLP (2013) opine that the advantages of early settlement are brought to the attention of disputants in spite of the fact that the ENE conference has never considered settlement as its ultimate goal.

\subsubsection{ENE Conference Is Held Early in the Litigation Process}

Under any court-connected mediation programme, disputants are generally encouraged to resort to mediation at an early stage. Commentators agree that ENE is best referred at an early stage of the litigation process (Brazil, 2007a; Germain, 2008a). Likewise, the ENE Conference is also held early as evidenced by the practice in the Western District of Missouri, where the first ENE conference is normally obtained within thirty (30) days from the date of filing the answer. In contrast, Eastern District of Pennsylvania holds the ENE Conference immediately after the filing of the appearance by the defendant (Di Pietro, 1997a). In the Northern District of California, it is held within 45 days upon the appointment of the neutral evaluator and 150 days upon the filing of a complaint. (Pietro, 1997b).

\subsubsection{Neutral Expert with Subject Matter Expertise}

Germain (2008b) states that the ENE Conference is hosted by an experienced neutral evaluator who has impeccable knowledge in the subject matter of the dispute. Remarkably, there can be a panel of three Early Neutral evaluators to provide a non-binding determination of an issue which the parties had been unable to resolve themselves and which could have developed into a large commercial dispute (Blake Lapthorn, 2014). In 
contrast, mediators are generally known to be process expert or subject matter expert or even possess both skills. Be that as it may, in complex disputes involving taxation, the mediator is usually chosen from among those who have in-depth experience in tax law, such as a retired judge or a barrister (McElwain \& Miller, 2012). In Malaysia, however, mediation especially court-connected mediation is still at its infancy stage. Therefore, it can be safely stated that the current pool of mediators are not necessarily experts in subject matter expertise even though on that point can be a fistful of them.

\subsubsection{Evaluative}

ENE is evaluative in nature of the evaluation is conducted by a neutral expert in a particular field. This feature is quite similar to evaluative mediation. Maycock (2001b) describes ENE as "neutral evaluation" and sometimes simply called case evaluation. The absolute magnitude of protracted complex litigation is often intimidating to disputants. Germain (2008c) mentions that the neutral evaluator listens to all parties and strive to see their strong points and failings of their positions before enormous litigation expenditures are incurred. Thus, the evaluative strength of ENE comes in the form of predicting the outcome of the trial with utmost caution and precision so that the disputants are briefed on the reality of their case and are able to make their decision with certainty.

\subsection{Goals of Early Neutral Evaluation Conferences in Contrast to Mediation}

This section discusses on the goals of ENE. In appropriate situations, a discussion on the goals of mediation (especially in terms of compatibility) is also included in order to distinguish it from the former, apart from determining in what ways ENE can support the process of mediating complex cases.

The distinctive goals of an ENE conference are as stated below:

\subsubsection{Early Organized Evaluation of Case Merits}

Lande (2008a) is of the view that implementing ENE early in the track of litigation provides disputants the opportunity to present a summary of its position before a neutral expert. The neutral expert will then provide an evaluation of the strengths and weaknesses of each disputant's case.

Commentators such as Germain (2008c) and Brazil (1990c) opine that introducing ENE at the early stage of the litigation process helps to realise one of the main goals of ENE, viz. to achieve an evaluation of the merits of the case. Early referral also prevents the raising of unnecessary issues; and in complex cases, critical legal issues can be identified by the neutral evaluator in order to provide a better settlement discussion among disputants (Macfarlanes, LLP, 2014). In contrast, mediation can also be introduced early in the litigation process and is generally known to guide disputants to achieve a "win-win situation" instead of a "win-lose situation". However, it is submitted that in complex cases, this form of guidance can somehow be illusory in practice especially when either of both disputants insist(s) on serious discussion based on grounds of merits prior to discussion on grounds of compromise. Although each disputant's perception about his or her factual and legal positions as well as information on interests and each other's needs are disclosed and discussed in the mediation session, this opportunity might not be fully utilised if the mediator has little experience or shallow knowledge of a particular dispute which is complex in nature.

\subsubsection{Early Settlement}

It is broadly known that disputants in mediation are usually geared towards settlement. There are a considerable number of commentators who emphasise settlement as the main goal of an ENE conference (Pearson, 2006b; Astor \& Chinkin; 1985; Brazil, Kahn, Newman, \& Gold, 1985). Engro and Lenihan (2008b), in identifying themselves from the rest, argue that ENE promotes settlement as well every bit capable of designing better ways to manage cases more efficiently.

\subsubsection{Empowerment of Disputants}

Empowerment of the individual is a strong motivation of any ADR mechanisms (Brown and Marriot 1996). This characteristic is shared by mediation and ENE. Yet, at times, this sensation of empowerment is illusory in mediation. In this connection, Arumugam (2000a) argues that if disputants felt compelled to enter into mediation for fear of judicial threat, the component of voluntary is lost. She further explains that in such a situation, there are power imbalances and disputants seeming surrender their control over their disputes. In contrast, even if ENE is court-mandated, the empowerment of the disputants remains intact. Brazil (2007b) points away that every disputant is exposed to every bit of communication with the neutral evaluator and arguments as good as evidence 'tendered' by each other (including their respective counsels) before the neutral evaluator. In such a spot, neither party can communicate secretively on an ex-parte basis (via phone, e-mails, letters or other electronic modes of communication) with the neutral evaluator until he has pulled in his written evaluation. 
It is posited that the bearing of the neutral evaluator, the disputants and their respective councils provide a secure program for discussion on merits especially in complex cases. This opportunity not only allows easy flow of arguments in a confidential and non-binding nature, but also provides disputants (as comfortably as their counsels) with a general idea of the expected decision of the court if a dispute is to be heard and disposed by way of a trial. This prediction of a court decision is made possible and is honest to a certain extent based on the expertise or past experience of the neutral evaluator obtained from his former job as a judge.

\subsubsection{Platform for Reducing Discovery Cost}

In complex cases, discovery of documents is generally an important routine in order to gather as much evidence as possible in order to hold up one's case. Therefore, according to Germain (2008d), ENE is an evaluative technique, and because it can be conducted very early, "discovery" expenditures might be shortened. A proper valuation of the case enables a disputant to identify and define the types of documents that need to be identified.

Under Rule 14 of the Minnesota State Supreme Court, case planning (a feature of ENE) is emphasised whereby ENE is defined as a conference which involves:

"...attorneys who will present the core of the dispute to a neutral evaluator in the presence of the parties. This occurs after the case is filed but before discovery is conducted. The neutral then give an assessment of the strengths and weaknesses of the case. If settlement does not result, the neutral helps narrow the dispute and suggests guidelines for managing discovery".

\section{Circumstances Where Early Neutral Evaluation Enhances Value of Mediation}

ENE is claimed to be suitable in situation where a case is "complex or has gotten out of control." Brazil (2007c) emphasises that ENE is able to address problems such as uncertainty about the midpoint of dispute, poor communication, unrealistic disputant(s) or counsel(s) and hesitance of a party to be the first to suggest settlement These identified circumstances meriting the referral of ENE prior to the use of mediation. These circumstances are succinctly stated below:

\subsection{Uncertainty about Crux of Dispute}

The RC 2012 governs civil proceedings in the Malaysian civil courts. The rules provide guidelines for the drafting of pleadings and also provide avenues for a disputant to exercise right to file certain applications meant to seek information from his adversary. Apparently, the general principles in drafting pleadings are that the cause of action (notably, any conditions which lead upwards to the claim) and the remedy sought must be expressed briefly in the pleadings. Most pleadings are filed under the premise that the subject matter in dispute has been distinguished. Be that as it may, disputants (and in some cases their own counsels) naturally face difficulty in identifying the crux of their dispute, especially in the early life of a complex case. Such uncertainty might affect negatively to the filing of interlocutory applications such as summary judgment (under Order 14 of the RC 2012), striking out (Order 18 rule 19 of the RC 2012) and disposal of cases in point of law and construction (Order 14A of the RC 2012) without any grounds of merit. In the absence of merits, the possibility for the court to dismiss such applications with costs is extremely probable. Apart from that, there is inclination of any of the disputant to file discovery and inspection of documents under the possession, custody or power of his adversary (Order 24 of the RC 2012). Nevertheless, the court may order any issue or question be determined prior to the making of any order for discovery of documents (Order 24 rule 4 of the RC 2012). In such a state of affairs, the disputants need to be guided legally especially in shaping the matters in dispute.

As previously mentioned, there are mediators who are either process expert or subject matter expert or even possess both skills. However, in Malaysia, they are broadly known to facilitate settlements rather than to judge disputes. Ooi (2004a) reminds that disputants, if given a choice, must choose a mediator who is subject matter expertise instead of process expertise. If a dispute is legally represented, the task of presenting the case before the mediator usually falls on his counsel. According to Chandran (1999a), if a party or his counsel is ill-prepared, he or his counsel would not be capable to talk about settlement terms effectively. In such a situation, it is difficult for the mediator (especially if he is not a subject matter expert) to identify the crux of a dispute by relying on the presentation of the case by a lawyer who presented it in a contentious rather than a persuasive manner.

Mediation is generally perceived as a flexible mechanism, allowing the mediator to vary each stage of the process to suit the needs of the disputants or to achieve certain objectives. Ooi (2004b) avers that during mediation, some mediators would encourage the disputants to seek "independent legal advice at certain point of the process, especially on important points such as a general indication of the position before embarking on mediation, and to consider whether mediation is appropriate." In this connection, the neutral evaluator is one 
professional who can dedicate sufficient time to advise the disputants on the reality of their positions and free from the element of biasness (Brazil, 2007d).

It is submitted that the identification of the crux of the disputes and various complex issues by the neutral evaluator in the ENE Conference would definitely assist the mediator during the forum stage of a follow-up mediation session. During this stage, the mediator would be able to identify the needs and priorities of the disputants in the joint session or even in the private session (caucus). It is further submitted that the mediator can strike this opportunity to discuss about probable options and best option in the problem solving stage; and even settlement agreement to conclude the mediation session.

\subsection{Addressing Specific Objective(s) at the Early Phase of Litigation}

Realistically, complex cases not only calls for extra judicial scrutiny, but also extra precautionary measure on the theatrical role of counsel to preserve their clients' interests. Counsels will usually emphasise on different matters in order to achieve specific objectives at a given point of time. Brazil (2007e) argues that most counsels are reluctant to use mediation at an early stage unless they have completed most of discovery or the presiding judge has made his rulings on all potential motions. Lande (2007b), on the other hand, shares similar view with Brazil on the point that counsels believe mediation is entirely appropriate when discovery has been conducted and further states that most counsels believe that it is imperative to obtain sufficient information prior to making any sound decision. In another writing, Brazil (2012a) stresses that disputants might opt for ENE to achieve some purpose "relatively early in the pre-trial period, then turn to mediation later when they are ready to get a hard run at getting a deal."

Where communication or strong emotions exist, mediation proves to be of great assistance. Chandran (1999b) stresses that mediation is an appropriate dispute resolution in situations when the disputants are concerned with their future dealings and would therefore do all that is necessary to save their relationship from being set down in a court battle. He further indicates that mediation becomes more of an obvious pick if the position of the disputants is that of cooperation and problem resolving. But the learned author shed no light on the issue as to whether mediation would be preferred in situation where the disputants are more concerned over their legal positions rather than their interests. Nolan-Haley (2013) avers that the fundamental aim of mediation is to facilitate settlement of disputes. Remarkably, she also observes that the neutral evaluator provides assistance both in settlement negotiations and in the planning of the case. Thus, if settlement negotiation fails, the disputants are guided on how to plan their case for trial. Under such circumstances, there is justification for the referral to ENE prior to the referral to mediation.

\subsection{Narrow Down and Clarify Issues}

Costello (1998) amongst others avers that the facilitative mediator is capable of clarifying issues and guide disputants to achieve their needs and interests but not their position. Obviously, however, if a person's mental state is so highly disturbed, he or she would find it difficult to identify the issues in complex cases. Notably, Clark and Davies (1992) lay down instances where mediation should not be used, notably in situations where one of the disputants are (i) "so seriously deficient of information" that caused any agreement entered to be challenged for the lack of informed consent; and (ii) where disputants are attempting to gain some tactical gain not related to the subject matter of dispute such as a "fishing expedition" to obtain more information, or as an attempt to prolong the proceedings. Casey and Wood (2007a) assert that a narrow-evaluative mediator would probably assist disputants to understand the strengths and weaknesses of their own positions and enlighten them about the probable outcomes at the trial.

But Brazil (2007d) argues that the evaluation by a neutral evaluator has "greater credibility" compared to the evaluation by a mediator. Brazil (2012b) cautions against choosing a mediator who emphasises too much on private caucusing or who is not familiar with other forms of subcultural mainstream. The neutral evaluator facilitates communication between the parties in the ENE Conference, before identifying key disputed issues (Casey and Wood, 2007b), guide them towards a mediated settlement or even narrow down their points of differences (Baksi \& Cross, 2012; Di Pietro, 1997c) and clarify issues in "large and complex cases" (Brazil, 1990d).

\subsection{Cross-party Communication and Power Imbalances in Mediation}

As the host of the session/conference, both the mediator and neutral evaluator control the order of speech and conduct of the mediation or ENE. Marutzky (2010) avers that the mediator addresses the underlying needs and interests of the disputants by controlling the line of communication between disputants. Essentially, both mediation and ENE promote cross-party communication and avoid power imbalances among the disputants. 
Although a number of commentators such as Arumugam (2000b) and Brown and Marriot (1996b) succinctly points out that the mediation process is a self-empowering process, power imbalances do occur at certain times. Examples where the mediator's hands are tied are aplenty, such as follows: (a) where a party believes that he has a good cause of action against the other party, and vice versa; (b) a dispute between a superior and his subordinate(s) and a dispute between husband and wife, where in both instances, power imbalances are the main hindrance towards settlement.

The ENE Conference provides opportunities for the disputants (and accompanying parties, including expert witnesses) to interact and argue out freely with each other (Brazil, 2007e). According to the American Arbitration Association, the ENE Conference encourages "direct communication" between disputants about possible claims and supporting evidence-especially in situations where there is disparity of views on how "the law applies to the case in question or what the case is worth." (American Arbitration Association). Garay (2014), among others, avers that the neutral evaluator encourages the disputants to be more receptive to "the referral of mediation (as an adjunct), and by identifying similarities and evaluating legal issues.

\section{Discussion on Findings}

This study shows that ENE is a viable mechanism that can be used to support the process of mediating complex cases. Both mechanisms possess more similarities than differences as shown below:

(a) ENE session usually takes place early in the case, whereas mediation does not only take place early in the case, but can occur at any time until the trial.

(b) Both ENE and mediation improve disputants' communication across party lines and mitigates power imbalances among disputants. The sessions are hosted by the neutral evaluator and the mediator respectively, thus allowing them to control the order of speeches and arguments of each disputant (or additional parties).

(c) Both ENE and mediation are suitable to be referred in complex cases. Both mechanisms allow opportunity for the neutral party to probe into the strengths and weaknesses of each disputant's legal position. ENE is suitable for complex cases where disputants place emphasis on expert evaluation of their respective legal positions. In contrast, mediation is suitable for complex cases involving creative solutions not provided by traditional litigation. Thus, when the two mechanisms are used simultaneously in the resolution of a dispute, there is higher possibility for the disputants to resolve their disputes. For example, the disputants can use the recommendation of the neutral evaluator during the mediation session, if both mutually choose to do so.

(d) Both ENE and mediation are capable of assisting disputants in reaching settlement. The disputants receive an assessment of their case by the neutral evaluator. If the disputants choose to have the neutral evaluator assist with settlement discussions, the session could result in a settlement agreement. Settlement terms are not necessarily limited to what is countenanced by law for it, they may include conditions which they have mutually agreed upon.

\section{Recommendations}

Recommendations to accommodate the use of ENE along mediation in managing complex civil cases in Malaysia are summarized as follows:

(a) The courts must not only be made aware of the value and viability of the ENE in managing complex civil cases, but also that there is room for its application under the Rules of Court 2012. The current provision under Order 34 rule 2 (2) (a) of the Rules of Court 2012 only stipulates on the court's power to issue directions on mediation. Thus, it should be amended to reflect the need to include referrals to the ENE and other appropriate modes of settlement. Furthermore, the Malaysian Federal Court Practice Direction No.5 of 2010 mentions that judges may employ "other modes of settlement" and need not necessary be mediation.

(b) In practice, lead counsels for each disputant must attend the ENE Conference. A mediation session can also be commenced after the ENE Conference. In the event that the mediation session is called off or discontinued for whatsoever reasons, it is recommended that counsels should guide their clients in evaluating their Best Alternative to a Negotiated Agreement (BATNA) or the Worst Alternative to a Negotiated Settlement (WATNA) or the Most Likely Alternative to a Negotiated Agreement (MLATNA). Obviously, lawyers who had attended and participated in the ENE Conference would be able to advise their clients accordingly on the likely outcome of a trial based on the advice given by the neutral evaluator in the ENE Conference.

(c) The Malaysian Judiciary should consider setting up an appropriate regulatory framework for ENE to provide public awareness of the benefits of ENE in the resolution of disputes. This involves the selection of experienced senior lawyers and even experienced retired judges. Literature shows that ENE can be conducted by an 
experienced judge. If judges are appointed to serve as neutral evaluator, policy makers might save costs by optimising the use of available experienced judicial officers in certain areas of law. However, the foreseeable limitations are that training judges as a neutral evaluator attracts costs. Furthermore, judges may also feel reluctant to act as early neutral evaluators for fear that this might add more work to their already busy daily schedule and task rating in terms of key-performance-indicator.

\section{Conclusion}

This study indicates that mediation is not the ultimate problem solver for all disputes, especially civil disputes. In some instances, such as disputes involving complex issues, ENE proves to be a better option, especially in identifying the crux the case and provides a reality check on the merits of a case. Nevertheless, ENE and mediation can work well together based on the many similarities rather than differences shared by the two mechanisms. Therefore, future research should include acquiring a model where the two mechanisms can be mentioned as constituent of a court resolution programme especially for the resolution of complex civil cases.

\section{References}

Alexander, R. (1999). Family Mediation under the Microscope. Australasian Dispute Resolution Journal, 10(3).

American Arbitration Association. (n. d.). Early Neutral Evaluation: Getting an Expert's Assessment. Retrieved from https://www.adr.org/aaa/faces/services/disputeavoidanceservices/earlyneutralevaluation?_afrLoop= $27651244483962 \& \_$afrWindowMode $=0 \&$ \& afrWindowId=7jddqorsx_251\#\%40\%3F_afrWindowId $\% 3 \mathrm{D} 7 \mathrm{jd}$ dqorsx_251\%26_afrLoop\%3D27651244483962\%26_afrWindowMode\%3D0\%26_adf.ctrl-state\%3D7jddqo rsx_295

Arumugam, V. (2000). Mediation of Family Disputes. (2000). INSAF. The Journal of the Malaysian Bar, $X X X I X(4)$.

Blake Lapthorn. (n. d.). Retrieved from http://www.bllaw.co.uk/services_for_businesses/mediation/our _experience.aspx\#ENE_experience

Brazil, W. D. (1990). A close Look at Three Court-Sponsored ADR Programs: Why They Exist, How They Operate, What They Deliver, and Whether They Threaten Important Values. The University of Chicago Legal Forum, (303).

Brazil, W. D. (2007). Early Neutral Evaluation or Mediation - When Might ENE Delivery More Value. Berkeley Law Scholarship Repository. Retrieved from http://scholarship.law.berkeley.edu/facpubs

Brazil, W. D. (2012). Early Neutral Evaluation (1st ed.). Chicago: American Bar Association.

Brazil, W. D., Kahn, M. A., Newman, J. P., \& Gold, J. Z. (1985). Early Neutral Evaluation: An Experimental Effort to Expedite Dispute Resolution 69. Judicature, 279.

Brown, H., \& Marriot, A. (1996). ADR Principles and Practice (1st ed.). London, Sweet and Maxwell.

Bryan, P. E. (1992). Killing Us Softly: Divorce Mediation and the Politics of Power. Buffalo Law Review, 20(2), 441-523.

Chandran, R. (1999). Mediation. Charting the Right Course for the New Millenium. Journal of the Malaysian Bar, XXVIII(3).

Court Backlog and Delay Reduction Programme. (2011, August). Malaysia Court Backlog and Reduction Program: A Progress Report, published by the World Bank.

Dayton, K. (1991). The Myth of Alternative Dispute Resolution in the Federal Courts. 76 Iowa Law Review, 889.

Early Neutral Evaluation. (n. d.). Retrieved from http://www.cand.uscourts.gov/ene

Engro, K., \& Lenihan, L. P. (2008). Understanding Early Neutral Evaluation in the Western District of Pennsylvania. 10 Lawyers J.3.

Fiss, O. M. (1984). Against Settlement. Yale Law Journal, 93, 1073-1090. http://dx.doi.org/10.2307/796205

Germain, K. B. (2008). Why Might ENE Be Effective In Trademark Cases? - The Use of Subject-Savvy Early Neutral Evaluators suggest Solutions to Significant Trademark/Trade Dress Disputes in Exparte and Interpartes Situation. February 2008, ALI-ABA COURSE OF STUDY MATERIALS.

Golberg, S. B., Sanders, F. E. A., Rogers, N. H., \& Cole, S. R. (2007). Dispute Resolution: Negotiation, Mediation and Other Processes (5th ed.). New York: Aspen. 
Hamid Sultan Abu Backer. (2012). Janab's Key to Civil Procedure - COMBINED RULES (The Rules of Court 2012 Annexed) (5th ed.). Kuala Lumpur: Janab (M) Sdn. Bhd.

Hassan, K. H., Yusoff, S. S. A., Mokhtar, M. F., \& Khalid, K. A. T. (2012). The use of technology in the transformation of business dispute resolution. European Journal of Law and Economics. http://dx.doi.org/10.1007/s10657-012-9375-7

Jacobs, P. (2005). A Recent Comparative History of Mandatory Mediation vs. Voluntary Mediation in Ontario, Canada. International Bar Association Mediation Newsletter.

Kelly, J. B. (2004). Family Mediation Research: Is There Empirical Support for the Field? Conflict Resolution Quarterly, 22(102), 3-35. http://dx.doi.org/10.1002/crq.90

Kornblum, G. O. (2012, Summer). Feature: Let's Look At Our Job as Litigators - Is There A Better Way Than A Completely Adversarial Posture? 38 San Francisco Attorney, 42.

Kovach, K. K. (1994). Mediation, Principles and Practice, St. Paul, 1994.

Kuhner, T. K. (2005). Court-Connected Mediation Compared: The Cases of Argentina and the United States. ILSA Journal of International and Comparative Law, 11(3), 1-36.

Land, J. (2008). The movement Toward Early Case Handling in Courts and Private Dispute Resolution. Ohio State Journal on Dispute Resolution, 24 Ohio St. J. On Disp. Resol.81.

Macfarlanes, LLP. (n. d.). Litigation in-brief. Retrieved from http://www.macfarlanes.com/media/320507/ early\%20neutral\%20evaluation.pdf

Mack, K. (2003). Court Referral to ADR: Criteria and Research, Australian Institute of Juridical Administration Inc. And the National Alternative Dispute Resolution Advisory Council.

Maycock, E. M. (2001, November). Mediator Focus: Early Neutral Evaluation. Utah Bar Journal, 36.

McElwain, C., \& Miller, M. (2012). Alternative Dispute Resolutions of Taxation Disputes, Institute of Chartered Accountants, Australia. Retrieved from http://www.charteredaccountants.com.au/News-Media/Charter/ Charter-articles/Tax/2012-11-Alternative-Dispute-Resolutions-of-Taxation-Disputes.aspx

McElwain, C., \& Miller, R. (2012). Alternative Dispute Resolutions of Taxation Disputes, Institute of Chartered Accountants, Australia. Retrieved from http://www.harteredaccountants.com.au/News-Media/Charter/ Charter-articles/Tax/2012-11-Alternative-Dispute-Resolutions-of-Taxation-Disputes.aspx

Nawi, N. F., \& Abdul Hak, N. (2013, March). Towards the Development of a Mandatory Family Mediation Program in the Malaysian Civil Legal System. Paper presented at the 6th World Congress on Family Law and Children's Rights, Sydney, Australia.

Ooi, C. S. S. (2004). The Role of Lawyers in Mediation: What the Future Holds. INSAF. Journal of the Malaysian Bar, XXXIII(4).

Pearson, Y. (2006). Early Neutral Evaluations: Applications To Custody And Parenting Time Cases Program Development And Implementation In Hennepin County, MINNESOTA, October, 2006, 44 Family Court Review, 672. http://dx.doi.org/10.1111/j.1744-1617.2006.00118.x

Perry, S. J., Marcum, T. M., \& Stoner, C. R. (2011). Stoner, Stumbling Down The Courthouse Steps: Mediators' Perceptions of the Stumbling Blocks to Successful Mandated Mediation in Child Custody and Visitation. Pepperdine Dispute Resolution Law Journal, 11, 441.

Pietro, S. (1997, December). Report to the Alaska Legislature: Alternative Dispute Resolution in the Alaska Court System. Alaska Judicial Council, 26, 1-48. Retrieved from http://www.ajc.state.ak.us/reports/adr.pdf

Stradley, Ronan, Steven, \& Young, LLP. (n. d.). A Snapshot of Early Neutral Evaluation. The ADR Advisor, 5. Retrieved from http://www.stradley.com/library/files/adradvisorspring_07.pdf

Tennille, F., Applebaum, L., \& Nees, A. T. (2010). Getting to Yes in Specialized Courts: The Unique Role of ADR in Business Court Cases. Pepperdine Dispute Resolution Law Journal, XI(35).

Wahab, A. A. (2013). Court-annexed and judge-led mediation in civil cases: The Malaysian experience. (Unpublished PhD thesis), Victoria University, Australia.

Welsh, N. A. (2011). Integrating "alternative" dispute, Resolution into bankruptcy: As simple (and pure) as Motherhood and apple pie? Nevada Law Journal, 11, 397.

Wissler, R. (2002). Ohio State Journal on Dispute Resolution, 17. 


\section{Copyrights}

Copyright for this article is retained by the author(s), with first publication rights granted to the journal.

This is an open-access article distributed under the terms and conditions of the Creative Commons Attribution license (http://creativecommons.org/licenses/by/3.0/). 